\title{
A Simple and Effective Method for Separating Meteorological from Nonmeteorological Targets Using Dual-Polarization Data
}

\author{
Alamelu Kilambi, FrÉdÉRIC Fabry, And VÉroniQue MEUnier \\ McGill University, Montreal, Quebec, Canada
}

(Manuscript received 3 October 2017, in final form 12 April 2018)

\begin{abstract}
To satisfy the needs of the meteorological and aeroecological communities wanting a simple but effective way of flagging each other's unwanted echo for a variety of different operational radar systems, we evaluated the ability of an estimate of depolarization ratio (DR) based on differential reflectivity $\left(Z_{\mathrm{DR}}\right)$ and copolar correlation coefficient $\left(\rho_{\mathrm{HV}}\right)$ measurements to separate both types of echoes. The method was tested with data collected by S- and C-band radars used in the United States and Canada. The DR-based method that does not require training achieved $96 \%$ separation between weather and biological echoes. Since the misclassifications are typically caused by isolated pixels in the melting layer or at the edge of echo patterns, the addition of a despeckling algorithm considerably reduces further these false alarms, resulting in an increase in correct identification approaching $99 \%$ on test cases.
\end{abstract}

\section{Wanted: Simple, robust target identification approach}

With the advent of dual-polarization weather radars, there have been several echo classification schemes for hydrometeor types as well as for the segregation of precipitation echoes from nonprecipitation echoes. Approaches based on polarimetric measurements (Zrnić and Ryzhkov 1999; Vivekanandan et al. 1999; Liu and Chandrasekar 2000; Zrnić et al. 2001; Schuur et al. 2003; Keenan 2003; Lim et al. 2005; Gourley et al. 2007; Marzano et al. 2008; Park et al. 2009; Chandrasekar et al. 2013; Bechini and Chandrasekar 2015; Grazioli et al. 2015; Besic et al. 2016; Roberto et al. 2017; to list a few) have now become the norm. For the weather surveillance radars used in the United States (referred to as WSR-88Ds or NEXRADs), many algorithms, such as precipitation accumulation, use the result of the target identification (ID) algorithm to determine how to process reflectivity or Doppler velocity data; proper target identification is hence key to the overall radar data quality.

Though the overall approach used to identify the target is becoming standardized across countries, each country uses its own recipes. These disparities partly reflect the different radar systems used and partly result from what targets are judged important to be properly

Corresponding author: Frédéric Fabry, frederic.fabry@mcgill.ca identified. These differences hurt the data exchanges across countries and affect nonmeteorological uses of weather radar data, such as for aeroecology, including tracking bird and insect movement. In an era where ground clutter is reasonably well eliminated, nonmeteorological echoes is increasingly synonymous with biological echoes, and there is increasing interest from ornithologists and entomologists to use the readily available data from meteorological radars for their studies (C. Francis 2015, personal communication).

Nonweather and weather echoes can be challenging to separate, in part because of the great diversity in values of reflectivity $(Z)$, differential reflectivity $\left(Z_{\mathrm{DR}}\right)$, differential phase $\left(\psi_{\mathrm{DP}}\right)$, and copolar correlation coefficient $\left(\rho_{\mathrm{HV}}\right)$; all of which can be measured. While weather echoes tend to have high $\rho_{\mathrm{HV}}(>0.9)$ and $Z_{\mathrm{DR}}$ near or just above unity (near or just above $0 \mathrm{~dB}$ ) but a wide range of $Z$ and $\psi_{\mathrm{DP}}$ values, biological echoes have no such limits except that $Z$ is generally below $30 \mathrm{~dB} Z$. As a result, in cases where the $\rho_{\mathrm{HV}}$ of biological echoes is very high, the WDR-88D algorithm tends to identify these echoes as precipitation (see Stepanian et al. 2016). Given that even state-of-the-art algorithms obtain erroneous results, there is a perceived need for a simpler approach that would 1) only initially separate meteorological from nonmeteorological echoes, 2) perform equally well on weather surveillance radars from different countries, and 3) ideally require minimum 

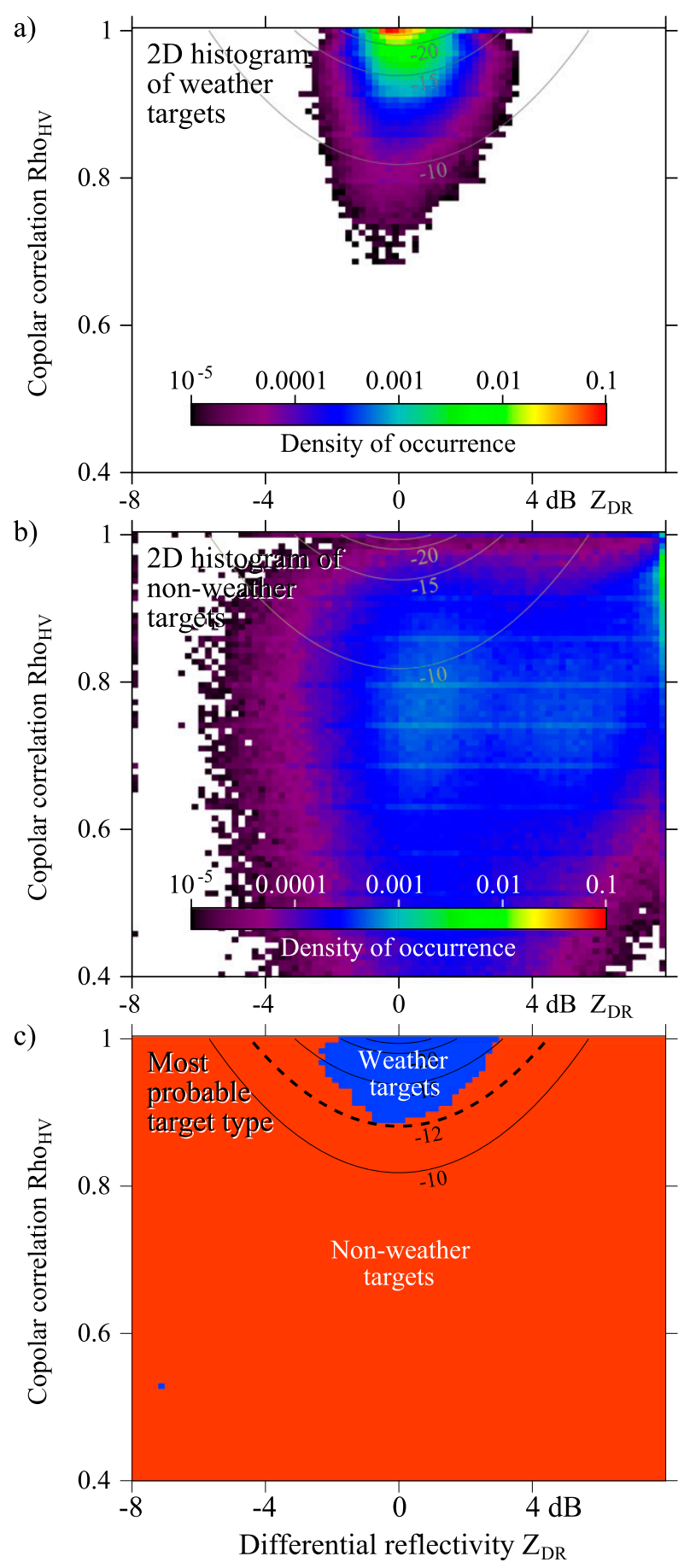

FIG. 1. Occurrence of precipitation and nonprecipitation targets in $Z_{\mathrm{DR}}-\rho_{\mathrm{HV}}$ space for our training dataset. (a) Density of occurrence of precipitating targets based on 2860835 targets of rain, snow, and melting snow. (b) Density of occurrence of nonprecipitating targets based on 1024054 targets. (c) Category of target most frequently observed for a given pair of $Z_{\mathrm{DR}}-\rho_{\mathrm{HV}}$ values. Gray curves are contours lines of four DR values, $-25,-20,-15$, and $-10 \mathrm{~dB}$, calculated using (1). In (c), a thick dashed line shows the $-12-\mathrm{dB}$ threshold used for the DR-based technique. Note how precipitating targets are concentrated in low $\mathrm{DR}$ values that are tuning so that nonexperts in radar could implement it. This is the task we chose to undertake.

\section{Basis: A nonsphericity test}

A commonly observed property of meteorological targets compared to other targets is how they are simultaneously uniform in shape (high $\rho_{\mathrm{HV}}$ ) and close to spherical $\left(Z_{\mathrm{DR}} \approx 1\right.$ in linear units). This is why circular depolarization ratio (CDR) has long been used as a mean to suppress weather echo contamination on aviation radars (White 1954). Though most operational radars cannot measure CDR because of their simultaneous transmission of pulses at horizontal and vertical polarization, a proxy quantity dubbed depolarization ratio (DR; Melnikov and Matrosov 2013; Ryzhkov et al. 2014, 2017) can be derived from available measurements using

$$
\mathrm{DR}=\frac{Z_{\mathrm{DR}}+1-2 Z_{\mathrm{DR}}^{1 / 2} \rho_{\mathrm{HV}}}{Z_{\mathrm{DR}}+1+2 Z_{\mathrm{DR}}^{1 / 2} \rho_{\mathrm{HV}}},
$$

where $Z_{\mathrm{DR}}$ is the differential reflectivity in linear scale. While DR computed in (1) has linear units and has values between 0 and 1 , we convert it into decibels $(\mathrm{dB})$ $\left[\mathrm{dB}(x)=10 \log _{10}(x)\right]$ for display purposes; in all latter discussions, values of DR will be in this $\mathrm{dB}$ unit. Figure 1 helps illustrate the relationship between values of $D R$, those of $\rho_{\mathrm{HV}}$ and $Z_{\mathrm{DR}}$, and the relative occurrence of meteorological and nonmeteorological targets from a training dataset described in section 3. As illustrated in Fig. 1, the DR of meteorological targets is small. The only weather echoes that have higher depolarization and that are not included in Fig. 1 are from hail and possibly melting graupel; but since those generally have reflectivities never observed in biological echoes ( $>35 \mathrm{dBZ})$, a reflectivity threshold can be applied to ensure that they are recognized as weather. For biological echoes, the high elongation of insects and the large size and diverse shapes of birds essentially ensure that either $Z_{\mathrm{DR}}$ is very different from unity (or $0 \mathrm{~dB}$ ) or $\rho_{\mathrm{HV}}$ is low, leading to larger DR values. Using the density of echo occurrence for different values of $Z_{\mathrm{DR}}$ and $\rho_{\mathrm{HV}}$ shown in Fig. 1 , we initially determined a threshold value of DR and reflectivity to separate meteorological echoes from nonmeteorological echoes;

rarely observed in nonprecipitating targets; beware of the logarithmic scale for the densities of occurrence when interpreting this figure. 
TABLE 1. FEI for the target ID algorithms before and after despeckling. Skill scores were computed based on 396260 pixels of precipitation (precip) and 192523 pixels of nonprecipitation (nonprecip) echoes. Bold values highlight the scores for the optimum DR value.

\begin{tabular}{|c|c|c|c|c|c|c|}
\hline $\begin{array}{c}\text { Target } \\
\text { ID method }\end{array}$ & $\begin{array}{c}\text { FEI } \\
\text { precip (raw) }\end{array}$ & $\begin{array}{c}\text { FEI } \\
\text { nonprecip (raw) }\end{array}$ & $\begin{array}{l}\text { HSS } \\
\text { (raw) }\end{array}$ & $\begin{array}{l}\text { FEI precip } \\
\text { (despeckled) }\end{array}$ & $\begin{array}{l}\text { FEI nonprecip } \\
\text { (despeckled) }\end{array}$ & $\begin{array}{c}\text { HSS } \\
\text { (despeckled) }\end{array}$ \\
\hline $\mathrm{DR}=-15 \mathrm{~dB}$ & $90.68 \%$ & $98.66 \%$ & 0.8542 & $95.02 \%$ & $99.83 \%$ & 0.9267 \\
\hline $\mathrm{DR}=-14 \mathrm{~dB}$ & $93.60 \%$ & $98.07 \%$ & 0.8909 & $97.25 \%$ & $99.68 \%$ & 0.9567 \\
\hline $\mathrm{DR}=-13 \mathrm{~dB}$ & $95.69 \%$ & $97.20 \%$ & 0.9146 & $98.38 \%$ & $99.39 \%$ & 0.9695 \\
\hline$D R=-12 \mathrm{~dB}$ & $97.15 \%$ & $95.82 \%$ & 0.9257 & $99.01 \%$ & $98.65 \%$ & 0.9714 \\
\hline $\mathrm{DR}=-11 \mathrm{~dB}$ & $98.15 \%$ & $93.60 \%$ & 0.9237 & $99.39 \%$ & $97.02 \%$ & 0.9631 \\
\hline $\mathrm{DR}=-10 \mathrm{~dB}$ & $98.85 \%$ & $90.08 \%$ & 0.9069 & $99.65 \%$ & $93.82 \%$ & 0.9408 \\
\hline
\end{tabular}

we found that on the 5 - and 10 -cm radars used in Canada and the United States, DR exceeding $-12 \mathrm{~dB}$ and $Z$ lower than $35 \mathrm{~dB} Z$ were generally associated with nonmeteorological echoes. The skill of this simple method was then evaluated on test cases.

\section{Data and processing}

The data used to generate Fig. 1 were collected from three sequences of WSR-88D data: KTYX (Fort Drum, New York) data from 11 volume scans from 1607 to 1702 UTC 31 October 2013 were used to derive statistics for widespread precipitation, a sector containing a mix of weather and wind farm echoes in the lower elevations being excluded from the computation; 10 volumes scans of KTYX data on 28 September 2013 from 0337 to 0442 UTC were used to sample bird echoes; and 2 volume scans of highly aligned insects from KJGX (Robins Air Force Base, Georgia) from 0002 to 0012 UTC19 April 2016 were used to complete the nonweather echo statistics creation. While the sample is small for training purposes, the training datasets included several common situations as well as a highly aligned insect case (Stepanian et al. 2016). The terms $Z_{\mathrm{DR}}$ and $\rho_{\mathrm{HV}}$ were averaged from their original resolution $\left(0.25 \mathrm{~km} \times 0.5^{\circ}\right.$ for WSR-88Ds in precipitation mode and $0.25 \mathrm{~km} \times 1^{\circ}$ in clear-air mode, $1 \mathrm{~km} \times 1^{\circ}$ for Canadian radars) to $1 \mathrm{~km} \times 1^{\circ}$ areas, and it is those values that are plotted in Fig. 1 and other figures. These reduced-resolution fields were also used to determine both the simple DR threshold $(-12 \mathrm{~dB})$ and the set of $Z_{\mathrm{DR}}-\rho_{\mathrm{HV}}$ combination that were more frequently associated with precipitation or with nonprecipitation echoes. At first glance based on Fig. 1c, the use of DR and the choice of its threshold value may not look optimal: the potential for wrong precipitation identification looks significant for $Z_{\mathrm{DR}}$ of $2-3 \mathrm{~dB}$ because of the DR formula; the use of a lower threshold may then be tempting to correct that weakness. But a lower threshold results in a rapid loss of skill in melting precipitation. And while one could design a formula better than (1) to follow the precipitation-to-nonprecipitation transition of Fig. 1c, biological echoes with high $\rho_{\mathrm{HV}}$ and moderate $Z_{D R}$ are rare; more importantly, this nonoptimal formula remains usable even when $Z_{\mathrm{DR}}$ estimates are biased by more than $1 \mathrm{~dB}$, relaxing somewhat the need for accurate $Z_{\mathrm{DR}}$ calibration and attenuation correction. In fact, a significant fraction of the dataset used in Fig. 1 had $Z_{\mathrm{DR}}$ values biased low, resulting in peak occurrence of precipitation echoes with $Z_{\mathrm{DR}}$ smaller than unity; but, one can see that a slight displacement of the histogram to higher $Z_{\mathrm{DR}}$ values would not change how we separate meteorological echoes from nonmeteorological echoes.

The DR approach was then evaluated on other events, namely, a volumetric scan of a stratiform event from KTYX at 0831 UTC 11 August 2015, one of bird migration from KTYX at 0403 UTC 27 September 2014 and one of highly aligned insects from KDGX (Jackson, Mississippi) at 0012 UTC 26 April 2016, taking care of echoes beyond $200 \mathrm{~km}$ that had precipitation. In both the training and evaluation sets, precipitation and nonprecipitation echoes were well separated, easing the validation task. That being said, as will be illustrated later, the DR approach being tested deals well with situations where both types of echoes are observed. The measured values of $Z_{\mathrm{DR}}$ and $\rho_{\mathrm{HV}}$ were used to compute DR and to separate meteorological from nonmeteorological echoes using only that information. Sometimes, especially in weak signal near the edge of echoes, $Z_{\mathrm{DR}}$ or $\rho_{\mathrm{HV}}$ may be poorly evaluated, resulting in an erroneous identification. To mitigate this problem, once an initial target ID determination has been made, a despeckling algorithm tries to remove false alarms: in a group of nine $1 \mathrm{~km} \times 1^{\circ}$ pixels ( 3 in azimuths $\times 3$ in range), if the ID of the center pixel is different from the majority of itself and that of its eight immediate neighbors, it is changed to reflect that majority opinion.

\section{Technique evaluation}

Table 1 summarizes the skill results obtained. It illustrates the great skill that this simple method has. Two methods were used to compute skill: The fraction of echoes correctly identified (FEI) for each target type and the overall Heidke skill score (HSS; Heidke 1926; Doswell et al. 1990), which is computed as 


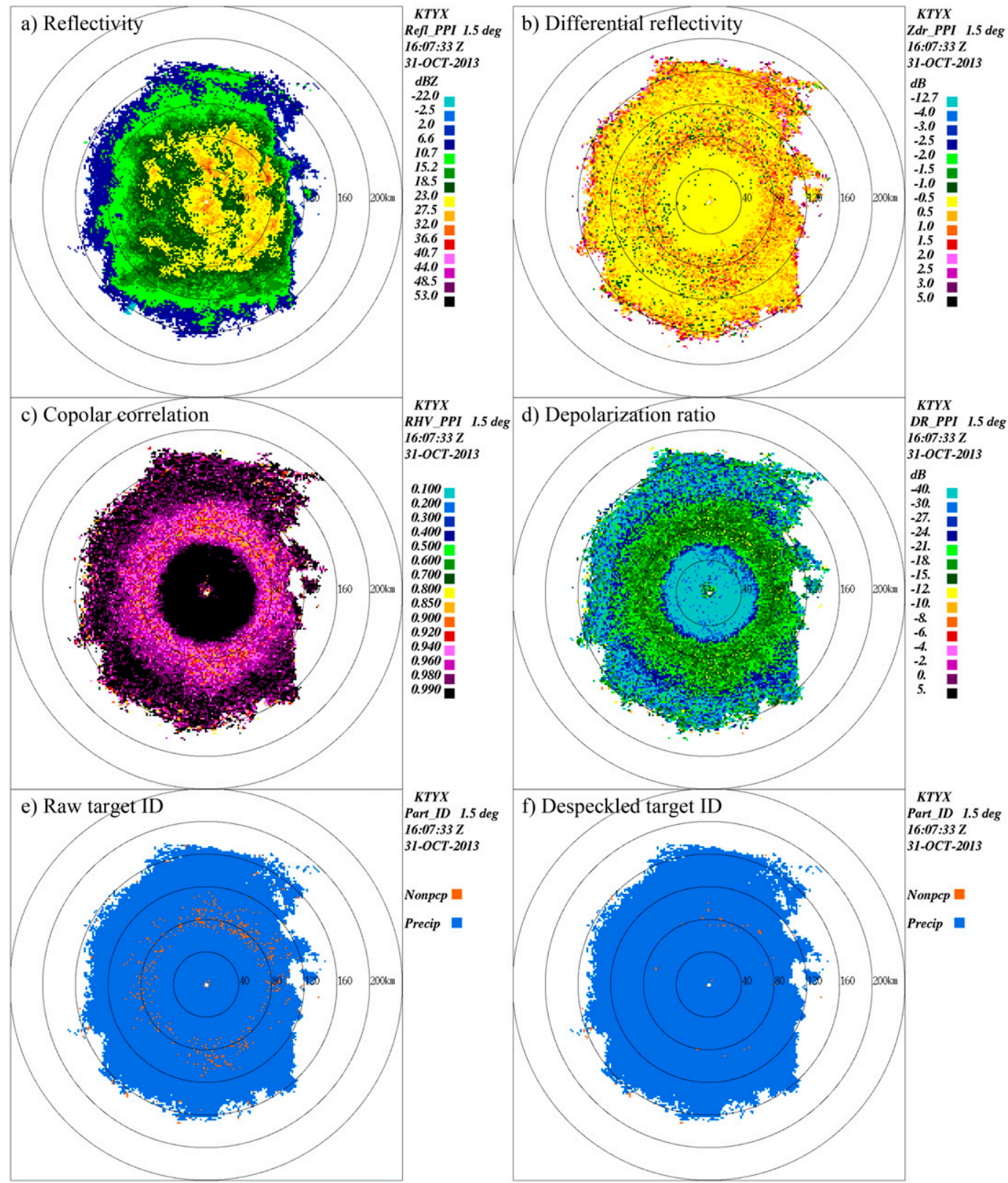

FIG. 2. PPIs of (a) $Z$, (b) $Z_{\mathrm{DR}}$, (c) $\rho_{\mathrm{HV}}$, (d) DR, (e) DR-based target ID, and (f) target ID after despeckling in widespread precipitation. Some pixels are misclassified in the brightband region because of elevated DR; much of that misclassification is removed by the despeckling algorithm.

$$
\mathrm{HSS}=\frac{\mathrm{NC}-\left(C_{12} C_{21} / T\right)}{T-\left(C_{12} C_{21} / T\right)},
$$

where $T$ is the number of classifications attempted; $\mathrm{NC}$ is the number of correct ones (precipitation or nonprecipitation echoes recognized as such); and $C_{12}$ and $C_{21}$ are the number of incorrect classifications in precipitation events and in nonprecipitation events, respectively. The crossover point that maximized the detection of both nonprecipitation and precipitation and minimized the false alarm rate was about $-12.5 \mathrm{~dB}$ on WSR-88D data; a similar test on Canadian C-band radar data had this threshold at $-12.7 \mathrm{~dB}$. The Heidke skill score that takes into account the larger dataset of precipitation than of nonprecipitation echoes in the WSR-88D evaluation dataset favored a $-11.7-\mathrm{dB}$ value. In this context the $-12-\mathrm{dB}$ choice proved to be a good one, and small variations $( \pm 0.5 \mathrm{~dB})$ around that value do not result in marked changes in performance. These skill scores also proved similar to those found on the training set. 


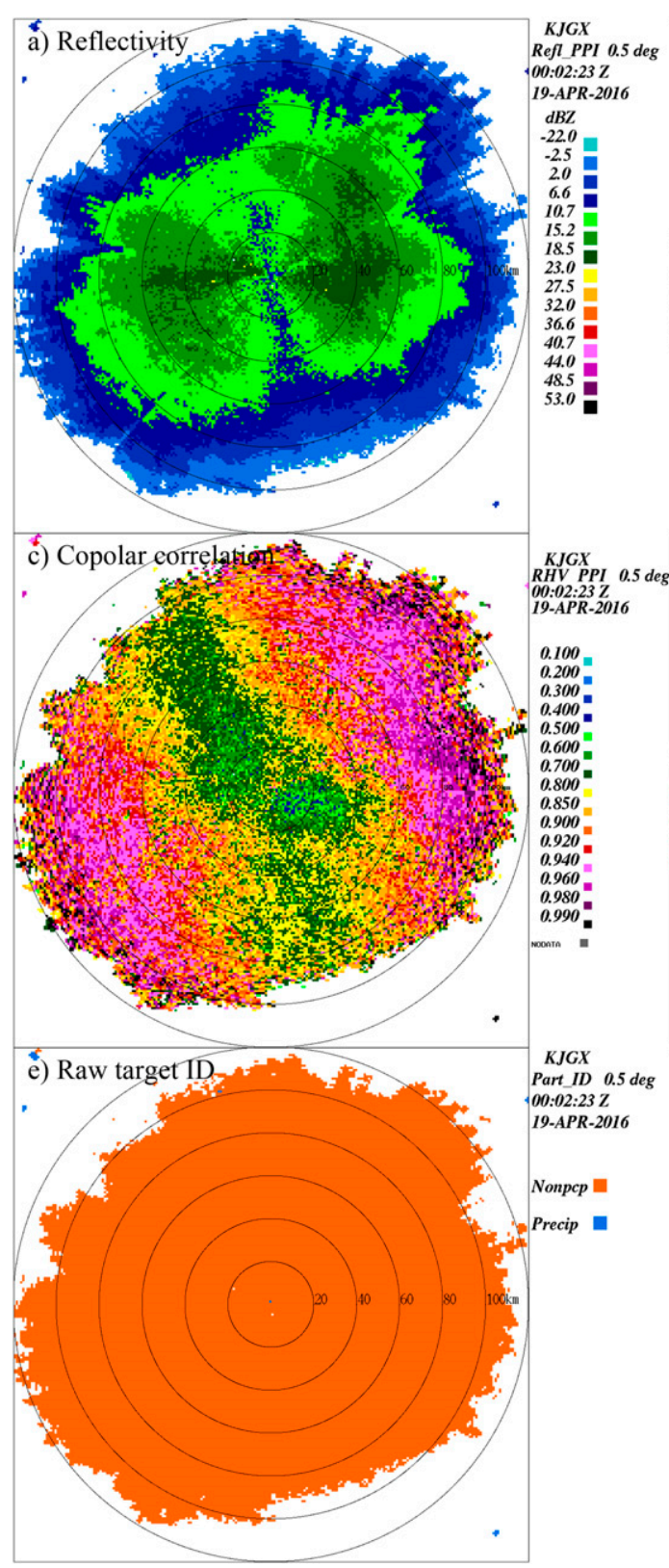

Figure 2 shows an example of the target ID performance in a precipitation event using the DR-based method. Most false alarms occur around the melting layer that appears on these PPI as a ring of enhanced reflectivity, higher differential reflectivity, and lower correlation around the $80-\mathrm{km}$ range; these are caused by the variety of shapes perceived by radar when snow melts. Under rare circumstances, if that shape variety is high enough, then computed depolarization exceeds our threshold and can lead to a false detection of nonweather echoes. But if these are isolated enough, they are mostly removed by the despeckling algorithm.

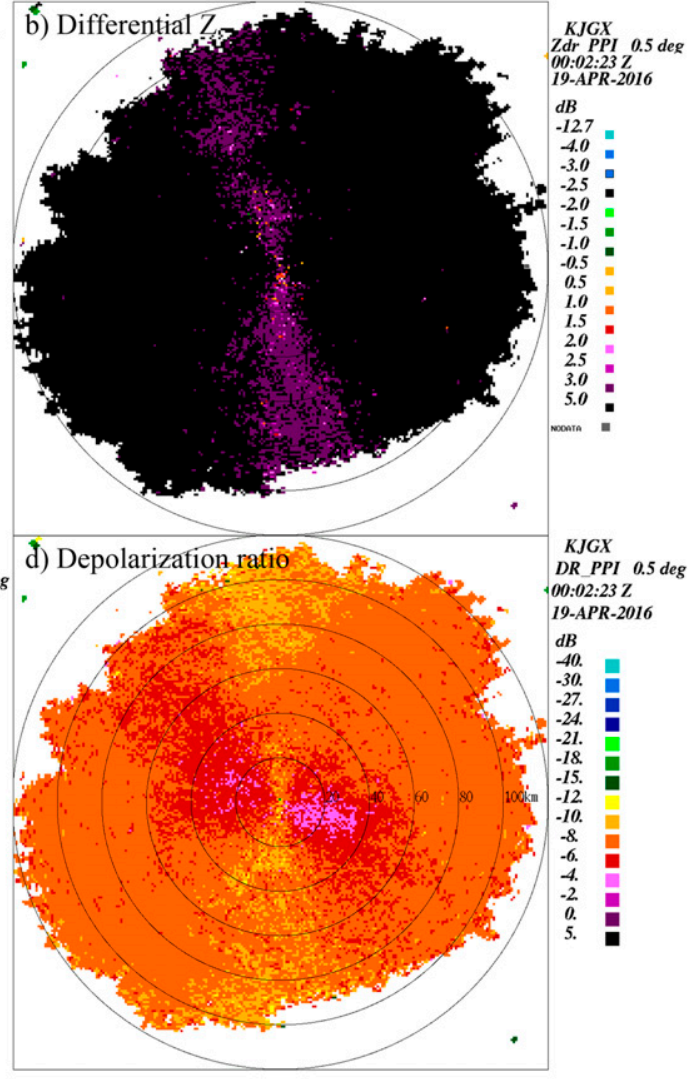

FIG. 3. PPIs of (a) reflectivity $Z$, (b) differential reflectivity $Z_{\mathrm{DR}}$, (c) copolar correction coefficient $\rho_{\mathrm{HV}}$, (d) computed depolarization DR, and (e) DR-based target ID in a highly aligned insect event that caused difficulties to the WSR-88D target ID algorithm (Stepanian et al. 2016). The high $Z_{\mathrm{DR}}$ values allowed the DR-based algorithm to recognize these echoes as nonweather.

At the other end of the spectrum, Fig. 3 shows a difficult event where insects were misclassified as precipitation by the WSR-88D algorithm (see Stepanian et al. 2016). However, the DR-based algorithm had no such problems in this case and properly identified all echoes as coming from nonweather targets: even if in some regions the copolar correlation of those insects was unusually high (Fig. 3c), it was their high differential reflectivity (Fig. 3b) that raised the computed depolarization (Fig. 3d) everywhere to a value that could not be associated with weather. As a result, all targets were identified as nonweather (Fig. 3e). 


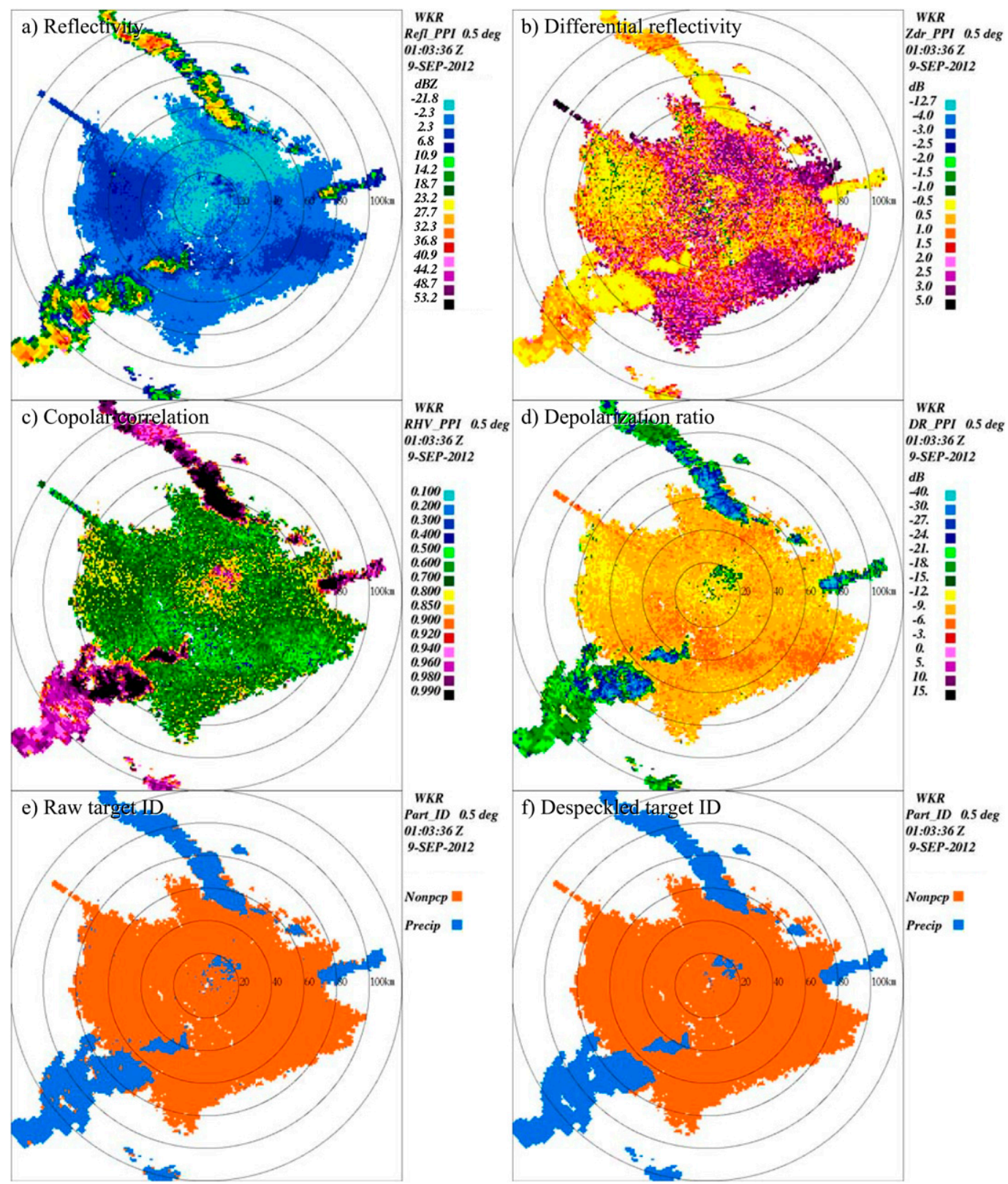

FIG. 4. As in Fig. 2, but from the King City C-band radar in an event with a variety of meteorological and nonmeteorological echoes. DR nicely separates nonweather echoes into warm colors and weather echoes into cold colors except for a few pixels near echo edges ( $\operatorname{bad} \rho_{\mathrm{HV}}$ estimates in weak signal).

To illustrate that this simple algorithm also works at other wavelengths, we present images from two events at $\mathrm{C}$ band (Fig. 4) and X band (Fig. 5) where insects and weather echoes are both present. On Fig. 4, most missed identification occurs on the edge of precipitation echoes (e.g., to the southwest in Fig. 4e) where poor estimates of correlation and differential reflectivity in weak signal lead to a high computed depolarization; many of these are, however, corrected by the despeckling algorithm (Fig. 4f). At X band (Fig. 5), the most significant identification problems arise from biased estimates of differential reflectivity caused by differential attenuation. Otherwise, a DR value of $-12 \mathrm{~dB}$ separates well the weather from the nonweather echoes at all major surveillance radar wavelengths.

\section{Why DR works, where it fails}

How does DR compare to traditional dual-polarization approaches for target identification? The main strength of the DR is that it naturally combines $\rho_{\mathrm{HV}}$ and $Z_{\mathrm{DR}}$ so 
a) Reflectivity

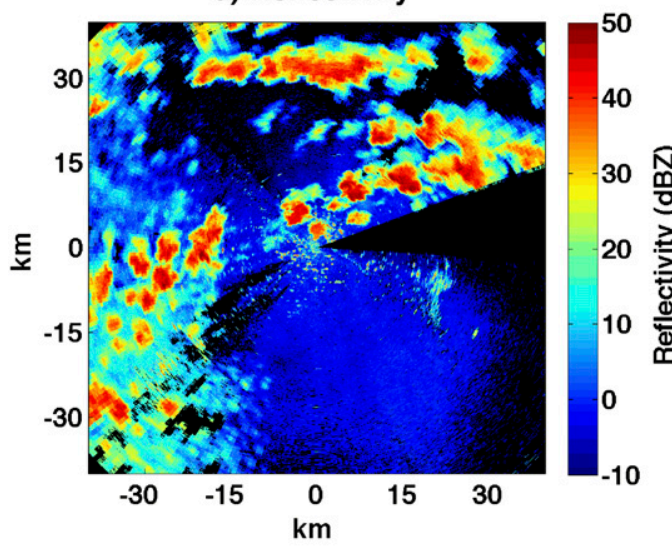

c) Rho hv

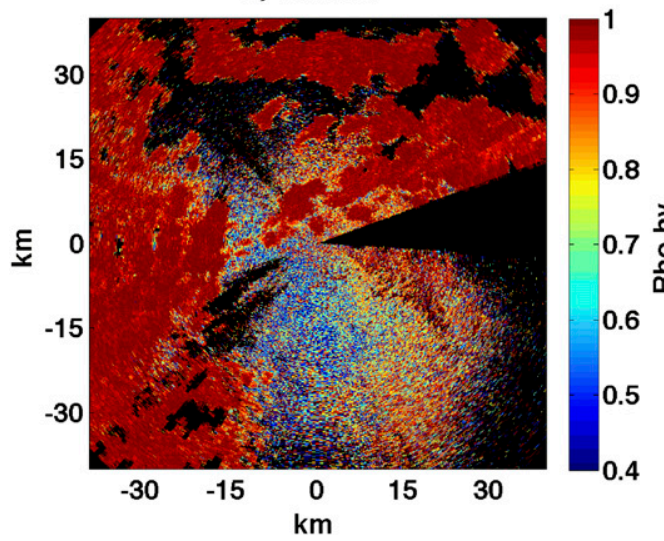

b) Zdr

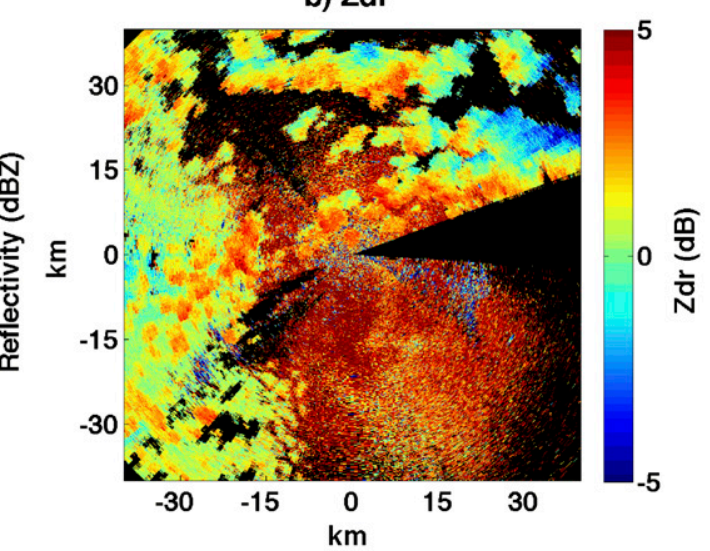

d) DR

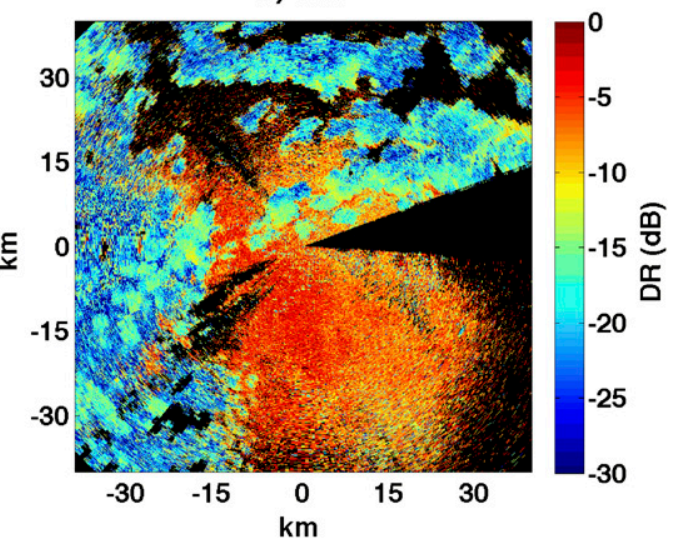

FIG. 5. PPIs at $1^{\circ}$ elevation of (a) $Z$, (b) $Z_{\mathrm{DR}}$, (c) $\rho_{\mathrm{HV}}$, and (d) computed depolarization DR from the sixth Doppler on Wheels (DOW-6) X-band radar at 0359 UTC 5 Jul 2015. A combination of insect, ground, and convective precipitation echoes can be observed. Nonweather echoes are visually recognized by their noisy texture in $\rho_{\mathrm{HV}}$ and/or $Z_{\mathrm{DR}}$, and those pixels have DR pixels in orange or red (greater than $-10 \mathrm{~dB}$ ); weather echoes have smooth $\rho_{\mathrm{HV}}$ and $Z_{\mathrm{DR}}$ fields, and those have DR pixels in green, cyan, or blue (less than $-15 \mathrm{~dB}$ ). The exception is a few pixels in the south (low signal) and a few behind several cells ( $35 \mathrm{~km}$ east and $20 \mathrm{~km}$ north of the radar) where the measured $Z_{\mathrm{DR}}$ has dropped below $-2 \mathrm{~dB}$ because of differential attenuation.

that low DR values correspond only to near-spherical targets and high DRs imply either elongated targets $\left(Z_{\mathrm{DR}}\right.$ $\neq 1$ ) or high shape diversity (low $\rho_{\mathrm{HV}}$ ). In other words, the DR separates uniform-spherical targets from the others by doing an "AND" combination of the $\rho_{\mathrm{HV}}$ and $Z_{\mathrm{DR}}$ tests; in contrast, traditional approaches based on fuzzy logic independently score elongation and shape diversity before combining the results. Hence, separation of

TABLE 2. Skill score of a target ID on the training set contrasting DR with fuzzy logic-based approaches. Fuzzy logic scores for target type $i=(1,2)$ were computed using $S_{i}=A P\left(\operatorname{target}=i \mid \rho_{\mathrm{HV}}\right)+(1-A) P\left(\operatorname{target}=i \mid Z_{\mathrm{DR}}\right)$, where $P(x \mid y)$ is the probability of observing $x$ given $y$ computed from the training dataset, and $A$ is a constant that is either 1 ( $\rho_{\mathrm{HV}}$-based test), $0\left(Z_{\mathrm{DR}}\right.$-based test), or the value that maximized the sum of FEI for both target types (optimum blend). Three scenarios are considered, one with perfect data and two with a $-0.4-\mathrm{dB}$ and a $+0.4-\mathrm{dB}$ bias on $Z_{\mathrm{DR}}$. Bold values highlight the most important scores of the two best target identification methods considered.

\begin{tabular}{|c|c|c|c|c|c|c|}
\hline $\begin{array}{l}\text { Target ID } \\
\text { method }\end{array}$ & $\begin{array}{l}\text { FEI precip } \\
\quad \text { (raw) }\end{array}$ & $\begin{array}{l}\text { FEI nonprecip } \\
\text { (raw) }\end{array}$ & HSS (raw) & $\begin{array}{c}\text { FEI precip } \\
\left( \pm 0.4-\mathrm{dB} Z_{\mathrm{DR}} \text { bias }\right)\end{array}$ & $\begin{array}{c}\text { FEI nonprecip } \\
\left( \pm 0.4-\mathrm{dB} \mathrm{Z} \mathrm{DR}_{\text {bias })}\right.\end{array}$ & $\begin{array}{c}\text { HSS } \\
\left( \pm 0.4 \mathrm{~dB} \mathrm{Z}_{\mathrm{DR}} \text { bias }\right)\end{array}$ \\
\hline$\rho_{\mathrm{HV}}$ alone $(A=1)$ & $94.216 \%$ & $91.606 \%$ & 0.8373 & - & - & - \\
\hline$Z_{\mathrm{DR}}$ alone $(A=0)$ & $91.683 \%$ & $77.479 \%$ & 0.6900 & $\begin{array}{l}81.875 \% \\
87.224 \%\end{array}$ & $\begin{array}{l}75.694 \% \\
79.932 \%\end{array}$ & $\begin{array}{l}0.5308 \\
0.6395\end{array}$ \\
\hline $\begin{array}{l}\text { Optimum fuzzy logic } \\
\text { using } \rho_{\mathrm{HV}} \text { and } Z_{\mathrm{DR}}\end{array}$ & $95.112 \%$ & $97.468 \%$ & 0.8939 & $\begin{array}{l}95.045 \% \\
93.962 \%\end{array}$ & $\begin{array}{l}97.238 \% \\
94.491 \%\end{array}$ & $\begin{array}{l}0.8911 \\
0.8534\end{array}$ \\
\hline $\mathrm{DR}=-12.7 \mathrm{~dB}$ & $96.303 \%$ & $96.718 \%$ & 0.9096 & $\begin{array}{l}96.311 \% \\
96.100 \%\end{array}$ & $\begin{array}{l}96.500 \% \\
96.977 \%\end{array}$ & $\begin{array}{l}0.9083 \\
0.9078\end{array}$ \\
\hline
\end{tabular}




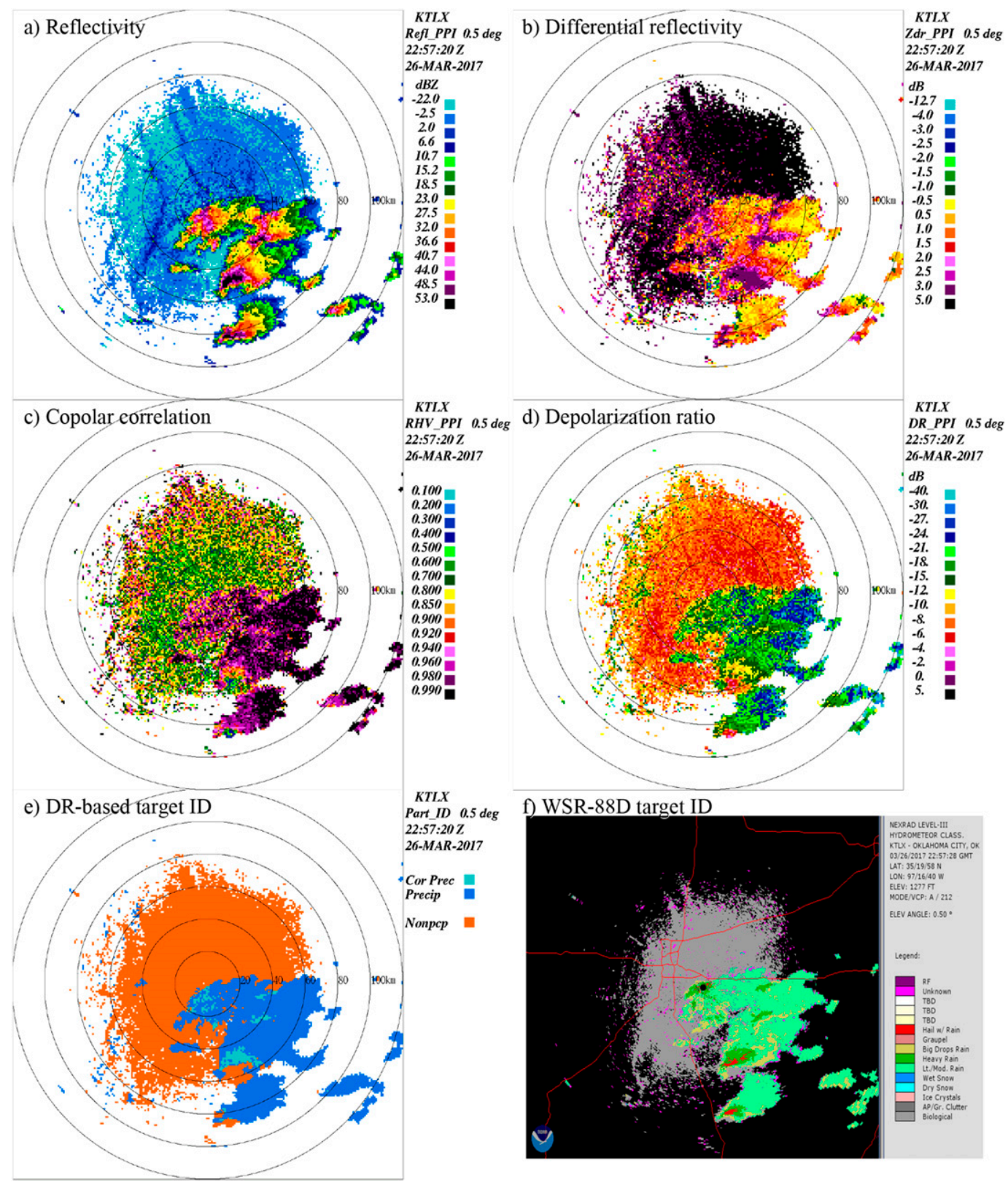

FIG. 6. PPIs of (a) $Z$, (b) $Z_{\mathrm{DR}}$, (c) $\rho_{\mathrm{HV}}$, (d) computed depolarization DR, (e) DR-based target ID, and (f) WSR-88D target ID during a hailstorm with insect echoes. In (e) pixels in cyan labeled as "Cor Prec" would have been identified as nonweather echoes but were corrected to precipitation because their reflectivity exceeded $35 \mathrm{~dB} Z$. In this case the performance of the simple DR-based algorithm compares well with that of the much more sophisticated WSR-88D algorithm in this complex situation.

nonprecipitation and precipitation targets is better with DR than with $\rho_{\mathrm{HV}}$ or $Z_{\mathrm{DR}}$ and comparable with an optimal linear combination of the two. Furthermore, the DR-based method is also less sensitive to $Z_{\mathrm{DR}}$ biases than the approach based on fuzzy logic (Table 2). This is an accidental consequence of the fact that contours of constant DR do not follow the shape of the $\rho_{\mathrm{HV}}-Z_{\mathrm{DR}}$ boundary that separates weather from nonweather echoes (Fig. 1c); thus, a small horizontal displacement of that boundary caused by a $Z_{\mathrm{DR}}$ bias does not result in many additional ID errors. That being written, like most algorithms, it works better given properly estimated inputs. In the absence of reasonable corrections, if $Z_{\mathrm{DR}}$ biases become large as can happen at $X$ band (see, e.g., Fig. $5 \mathrm{~b}$, in the northeast when $Z_{\mathrm{DR}}$ gets below $-2 \mathrm{~dB}$ ), estimated depolarization rises rapidly and the algorithm 
starts to fail. With a Heidke skill score of nearly 0.91 , the DR-based technique is also largely superior to using the standard deviation of differential phase (Heidke skill score of 0.60 on the events studied).

One of the weaknesses of the DR-based technique is its reliance on good-quality $\rho_{\mathrm{HV}}$ estimates. Hence, false alarms will occur in very weak echoes, where low signal strength affects $\rho_{\mathrm{HV}}$ data quality, as well as in heavy convection, when $\rho_{\mathrm{HV}}$ values are lowered by hail (Fig. 6), melting graupel, or strong gradients of $\psi_{\mathrm{DP}}$ in azimuth or elevation. We find that false alarms in precipitation are reduced when nonprecipitation echo identification is accepted only for reflectivity lower than $35 \mathrm{dBZ}$ (Fig. 6), recognizing that it is an imperfect solution to a complex problem.

\section{Concluding remarks}

In this work a target ID approach combining information from $Z_{\mathrm{DR}}$ and $\rho_{\mathrm{HV}}$ to estimate depolarization was found to separate meteorological echoes from nonmeteorological with great skill on a variety of operational radar systems without the need for extensive tuning. While in many ways such a simple approach may be considered a step backward compared to the current state of the art, it will appeal to researchers looking for a uniform way of distinguishing meteorological and nonmeteorological radar echoes across several radar systems. Furthermore, nothing prevents using DR as an input to future ID algorithms given its great ability to separate meteorological and nonmeteorological echoes.

Acknowledgments. This project was undertaken with the financial support of the Government of Canada provided through the Department of the Environment through Grants and Contributions GCXE16E336. We also thank Josh Wurman and his colleagues at the Center for Severe Weather Research, who provided us with the data used in Fig. 6, whose collection was made possible by NSF Grant NSF-AGS-1361237.

\section{REFERENCES}

Bechini, R., and V. Chandrasekar, 2015: A semisupervised robust hydrometeor classification method for dual-polarization radar applications. J. Atmos. Oceanic Technol., 32, 22-47, https:/ doi.org/10.1175/JTECH-D-14-00097.1.

Besic, N., J. Figueras i Ventura, J. Grazioli, M. Gabella, U. Germann, and A. Berne, 2016: Hydrometeor classification through statistical clustering of polarimetric radar measurements: A semi-supervised approach. Atmos. Meas. Tech., 9, 4425-4445, https://doi.org/10.5194/amt-9-4425-2016.

Chandrasekar, V., R. Kernen, S. Lin, and D. Moisseev, 2013: Recent advances in classification of observations from dual polarization weather radars. Atmos. Res., 119, 97-111, https:// doi.org/10.1016/j.atmosres.2011.08.014.
Doswell, C. A., III, R. Davies-Jones, and D. L. Keller, 1990: On summary measures of skill in rare event forecasting based on contingency tables. Wea. Forecasting, 5, 576-585, https:// doi.org/10.1175/1520-0434(1990)005<0576:OSMOSI>2.0.CO;2.

Gourley, J. J., P. Tabary, and J. P. du Chatelet, 2007: A fuzzy logic algorithm for the separation of precipitating from nonprecipitating echoes using polarimetric radar observations. J. Atmos. Oceanic Technol., 24, 1439-1451, https://doi.org/ 10.1175/JTECH2035.1.

Grazioli, J., D. Tuia, and A. Berne, 2015: Hydrometeor classification from polarimetric radar measurements: A clustering approach. Atmos. Meas. Tech., 8, 149-170, https://doi.org/ 10.5194/amt-8-149-2015.

Heidke, P., 1926: Berechnung des Erfolges und der Güte der Windstärkevorhersagen im Sturmwarnungsdienst. Geogr. Ann., 8, 301-349, https://doi.org/10.2307/519729

Keenan, T. D., 2003: Hydrometeor classification with a C-band polarimetric radar. Aust. Meteor. Mag., 52, 23-31.

Lim, S., V. Chandrasekar, and V. N. Bringi, 2005: Hydrometeor classification system using dual-polarization radar measurements: Model improvements and in situ verification. IEEE Trans. Geosci. Remote Sens., 43, 792-801, https://doi.org/ 10.1109/TGRS.2004.843077.

Liu, H., and V. Chandrasekar, 2000: Classification of hydrometeors based on polarimetric radar measurements: Development of fuzzy logic and neuro-fuzzy systems, and in situ verification. J. Atmos. Oceanic Technol., 17, 140-164, https://doi.org/10.1175/1520-0426(2000)017<0140: COHBOP $>2.0 . \mathrm{CO} ; 2$.

Marzano, F. S., D. Scaranari, M. Montopoli, and G. Vulpiani, 2008: Supervised classification and estimation of hydrometeors from C-band dual-polarized radars: A Bayesian approach. IEEE Trans. Geosci. Remote Sens., 46, 85-98, https://doi.org/ 10.1109/TGRS.2007.906476.

Melnikov, V., and S. Matrosov, 2013: Estimations of aspect ratios of ice cloud particles with the WSR-88D radar. 36th Conf. on Radar Meteorology, Breckenridge, CO, Amer. Meteor. Soc., 245, https://ams.confex.com/ams/36Radar/webprogram/ Paper228291.html.

Park, H., A. Ryzhkov, D. Zrnić, and K.-E. Kim, 2009: The hydrometeor classification algorithm for the polarimetric WSR-88D: Description and application to an MCS. Wea. Forecasting, 24, 730-748, https://doi.org/10.1175/ 2008W AF2222205.1.

Roberto, N., L. Baldini, E. Adirosi, L. Facheris, F. Cuccoli, A. Lupidi, and A. A. Garzelli, 2017: Support vector machine hydrometeor classification algorithm for dualpolarization radar. Atmosphere, 8, 134, https://doi.org/ 10.3390/atmos8080134.

Ryzhkov, A., P. Zhang, Q. Cao, S. Matrosov, V. Melnikov, and M. Knight, 2014: Measurements of circular depolarization ratio with the radar with simultaneous transmission/reception. Extended Abstracts, Eighth European Conf. on Radar in Meteorology and Hydrology (ERAD 2014), Garmisch-Partenkirchen, Germany, DWD and DLR, 11.3, http://www.pa.op.dlr.de/erad2014/ programme/ExtendedAbstracts/232_Ryzhkov.pdf.

_ _ _ a and Coauthors, 2017: Estimation of depolarization ratio using weather radars with simultaneous transmission/ reception. J. Appl. Meteor. Climatol., 56, 1797-1816, https:// doi.org/10.1175/JAMC-D-16-0098.1.

Schuur, T., A. Ryzhkov, P. Heinselman, D. Zrnić, D. Burgess, and K. Scharfenberg, 2003: Observations and classification of echoes with the polarimetric WSR-88D radar. NSSL Rep., 46 pp. 
Stepanian, P. M., K. G. Horton, V. M. Melnikov, D. S. Zrnić, and S. A. Gauthreaux Jr., 2016: Dual-polarization radar products for biological applications. Ecosphere, 7, e01539, https:// doi.org/10.1002/ecs2.1539.

Vivekanandan, J., D. S. Zrnić, S. M. Ellis, R. Oye, A. V. Ryzhkov, and J. Straka, 1999: Cloud microphysics retrieval using S-band dualpolarization radar measurements. Bull. Amer. Meteor. Soc., 80, 381-388, https://doi.org/10.1175/1520-0477(1999)080<0381: CMRUSB $>2.0 . \mathrm{CO} ; 2$.
White, W. D., 1954: Circular radar cuts rain clutter. Electronics, 27, 158-160.

Zrnić, D. S., and A. V. Ryzhkov, 1999: Polarimetry for weather surveillance radars. Bull. Amer. Meteor. Soc., 80, 389-406, https:// doi.org/10.1175/1520-0477(1999)080<0389:PFWSR > 2.0.CO;2.

_, _ J. J. Straka, Y. Liu, and J. Vivekanandan, 2001: Testing a procedure for the automatic classification of hydrometeor types. J. Atmos. Oceanic Technol., 18, 892-913, https://doi.org/ 10.1175/1520-0426(2001)018<0892:TAPFAC $>2.0 . C O ; 2$. 